\title{
Illusory Scene and Immersive Space in Tintoretto's Theatre
}

Gabriella Liva

Massimiliano Ciammaichella

Abstract

The perspective analysis of some canvases by Jacopo Robusti is the result of a research which involved, within the University of Padua, architecture and art historians with representation scholars, to share knowledges about one of the most important Venetian artists of the second half sixteenth century. The study, continued in collaboration with the luav University of Venice professors and students, focused on an exhibition proposal at the Sala Capitolare of the Scuola Grande di San Marco in Venice, where hopefully some of paintings will return to their original destination.

The main objective concerns the creation of an experiential itinerary, organized by a sensitive narration that starts in the same act of its fruition, to allow the observer a critical interaction dependent on knowledge process of the works and their evoked spaces, without the aid of controllers or digital viewers.

Keywords

Tintoretto, architectural perspective, exhibit, video mapping, scenography.
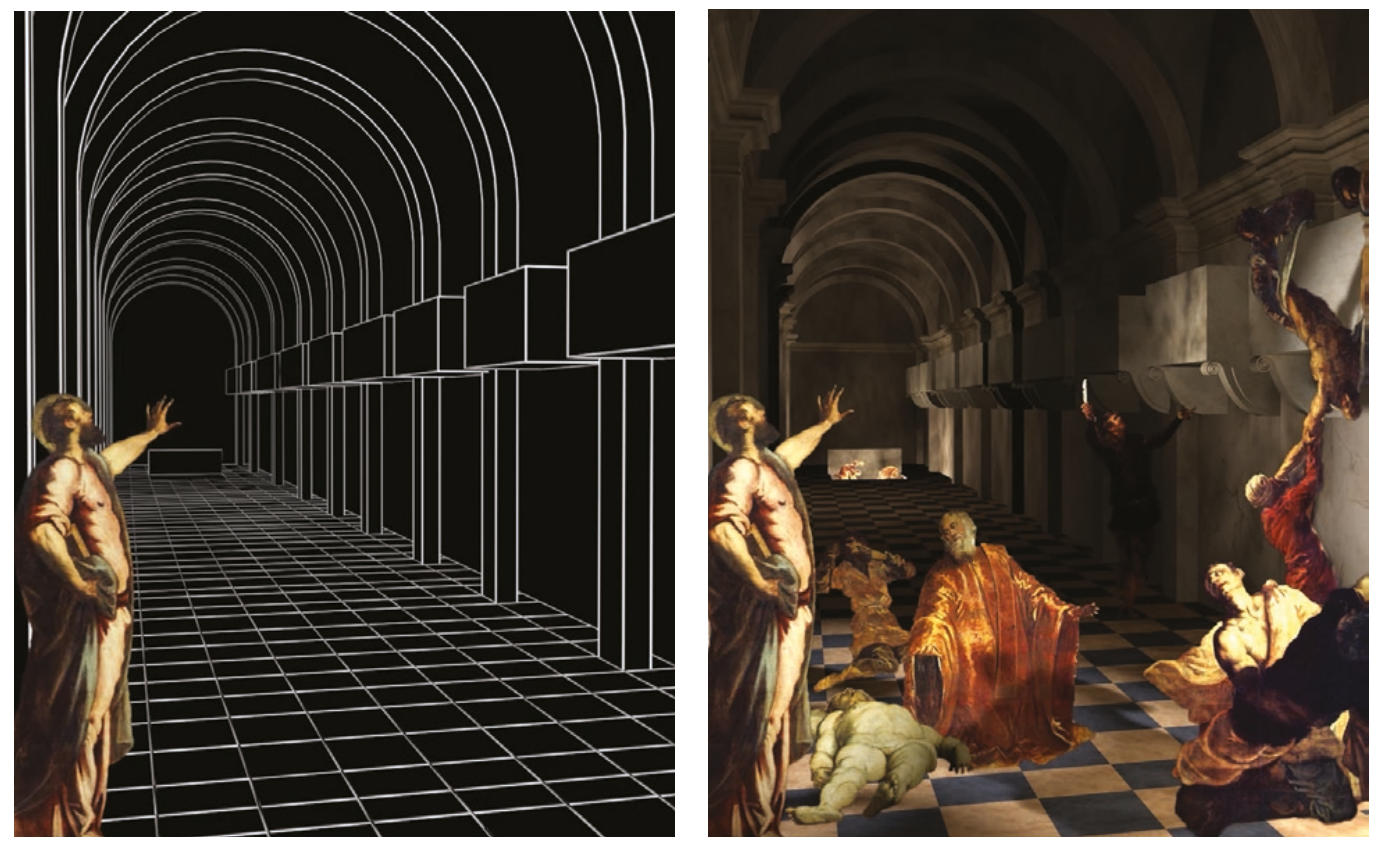
The essay documents the results of a research aimed at enhancing the artistic and cultural heritage offered by Tintoretto's work, through an exhibition mode able to guarantee a knowledge experience increased using advanced digital interaction devices.

Starting from the most up-to-date artistic historiography of Tintoretto's work, the analysis conducted highlights the Venetian artist's relationship with architecture, which has remained unexplored or limited to a few essays that underline an uncommon spatial research. Considerations of the scholars Sergio Marinelli, Erasmus Weddigen, Michael Matile and Martina Frank have laid the basis for a further in-depth investigation of the relationship established by Tintoretto with the painted space, based not only on a precise knowledge of built architecture, but also on a profound admiration for the theatrical scenic space [Marinelli 1980, Weddigen 1991, Matile 1996, Frank 1996].

Following the renovatio urbis, imposed by the Doge Andrea Gritti - for which the reconfiguration action of Venice image is evident -, the theoretical and material examples due especially to Sebastiano Serlio and Jacopo Sansovino, together with the uncontested contact with Tuscan-Roman figurative culture, become a source of inspiration and pictorial transposition of the urban environment proposed by Tintoretto.

In his early paintings the architecture interest took on a secondary role, relegating it to the background of the narration, but from the mid-Forties of the sixteenth century, with the Christ among the Doctors, Christ and the Adulteress and Miracle of the Slave, the architectural space component became an integral part of the composition, which focuses on linear perspective. This method is understood as a technical and conceptual means of controlling the spatial configuration, aided using papier-mâché maquettes in which the painter, according to Carlo Ridolfi - who metTintoretto's son, Domenico - placed wax and clay statuettes to verify the position of the characters dressed in rags, on which he carefully elaborated folds and poses of the limbs. In other cases, if necessary, he increases their scale and suspends them with wires from the beams to check their foreshortening, then he builds "small houses and relief-perspectives made of boards and cardboard, inserting small lights for the windows" [Ridolfi 1648, p. 7] and uses candles to simulate the different light sources to be reproduced in the painting [Marinelli 1980, p. 319].

This research, found in the scenic practice, can be traced back both to his theoretical education, which took place in Sebastiano Serlio's books in which we find descriptions of the performant spatiality and indications on the arrangement of lights, and to the painter's familiarity with theatrical spaces and, in particular, his friendship and frequentation of Ruzzante, Pietro Aretino and Andrea Calmo [De Vecchi 1972, pp. I0 I- I32].

It is evident that the influence exerted by Serlian representations of ephemeral theatrical scenes - combined with the architectural practice and perspective skills of the Bolognese architect - adheres to Sansovinian petrified translation of Doge Gritti's idea, leading Tintoretto to transform the painted space into a credible urban stage on which to place the biblical narrations.

\section{Research and Case Study}

The research establishes the aim of analysing the coherence, verifying the precision of perspective technique used, also reflecting on the intentional deformations and pictorial corrections chooses by Tintoretto, in a strategic and controlled approach, especially in his more mature works. A predominant architectural component is evident in these words, and so we have tried to understand: the relationship with the biblical events narrated; the scenic setting in which the painted architecture becomes the structuring foundation of the entire composition; the visual and physical kinematic, regulated by the point of view of the observer forced to move in the multiple narration of the mise-en-scène. The implementation of precise perspective rules offered the possibility of restitution the painted space, with a rigorous inverse method and with adequate mathematical modelling software, demonstrating, in enhancing the written historical evidence, the real possibility that Tintoretto used real small-scale maquettes, necessary to compositions design in which to insert the lights and then the characters that inhabit them (figs. I-2). 
Fig. I.The Miracles of Saint Mark, perspective restitution [Gabriella Liva 2020].
The canvas dedicated to The Miracles of Saint Mark is part of the chosen case studies and represents a masterfully constructed setting, made even more credible when associated, in Weddigen's hypothesis, with two other masterpieces: the Removal of the Body of St Mark and St Mark Saving a Saracen During a Shipwreck, in its primordial composition [Grosso Guidarelli 2019, p. 106]. If it is considered singularly, or in a unitary perspective strategy, at the moment of its appearance inside the Sala Capitolare of the Scuola Grande di San Marco, it aroused particular astonishment, if not the wonder ensured by the attempt to merge the hall real space with the place of the depicted scene. The context is represented by a majestic old-style portico that rises above a polychrome chessboard floor, making the articulated composition not immediately intelligible.
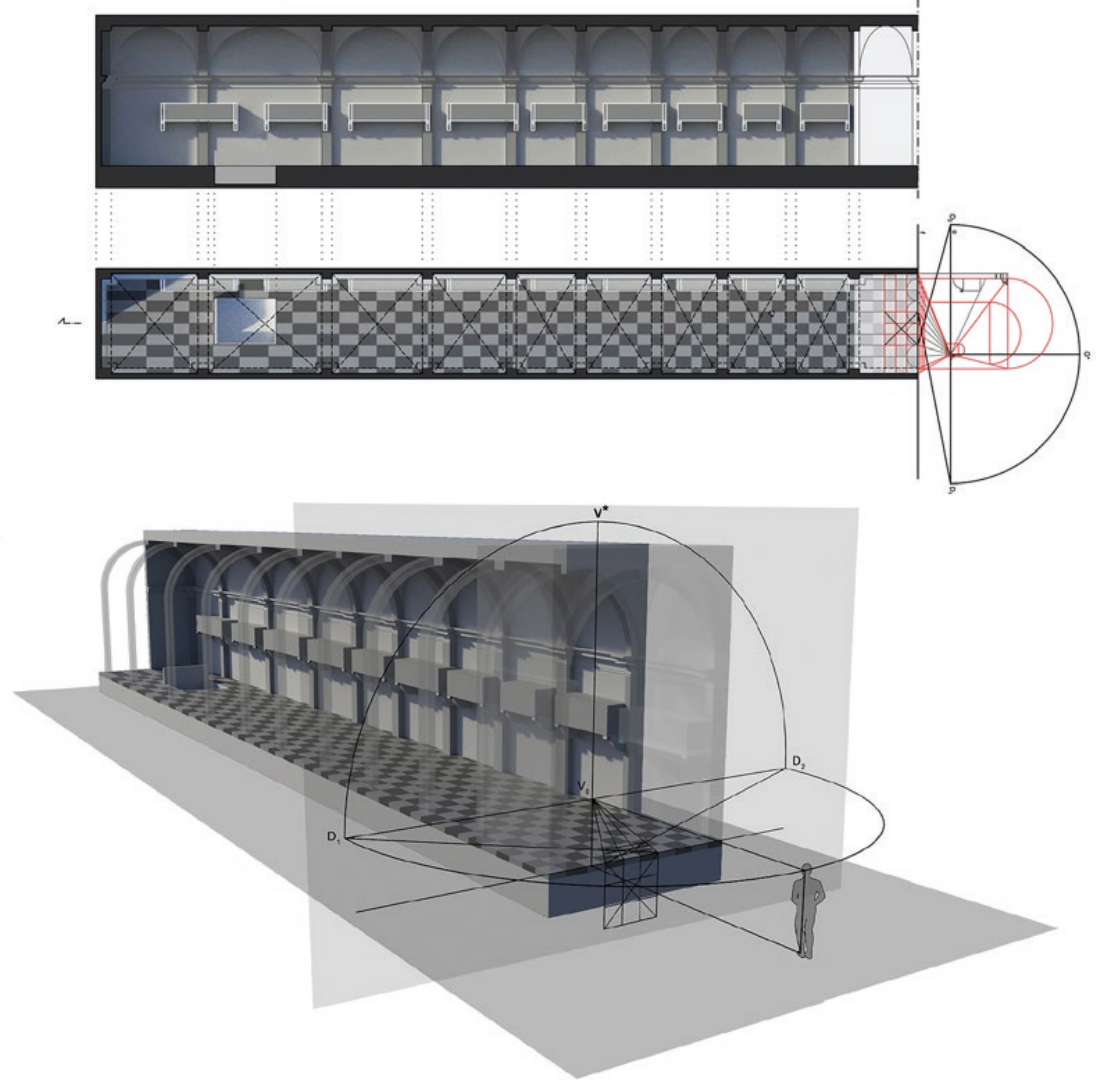

As with other works, here we are not dealing with a static setting relegated to a simple background, but with a geometrically structured space in a direct dialogue with the characters who activate it, participating in their actions or accompanying the viewer in specific painting areas, so as to encourage a multiple reading of the events narrated. The study of the work included a detailed analysis of the various compositional elements that make it up, the identification and classification of which become of primary importance for the exhibition layout proposal. Inside the space, punctuated by the rhythm of the cross vaults interspersed with large round arches, "there appear in a long portico many sepulchres hanging on the walls, drawn by a beautiful perspective" [Ridolfi 1648, pp. 14-15], whose orthogonal profiles to the painting converge towards a single vanishing point. It is positioned on the left side in correspondence of the pulse of the saint who indicates, to the viewer, the recognition of his body. The characters depicted are distributed along the nave, according to three registers: in the foreground a group of people is represented on the right, including a possessed man taken from behind and breathing sulphurous vapours; in the centre the client Tommaso Rangone kneeling and, on the left, the majestic figure of St. Mark in the act of revealing the discovery of his earthly body; then the viewer assists the extraction of the body from the hanging sepulchre and, in the background, the vain search for the body of the saint inside an earthly sepulchre. 


\section{Methodology}

Considering the narrative sequence of painted events, the study, continued in collaboration with University luav of Venice professors and graduating students, focused on an exhibition setting proposal and visual entertainment to be reproduce in the Sala Capitolare of the Scuola Grande di San Marco in Venice, trying to retrieve the close relationship between the real space of the hall and the illusory space evoked by represented scenes (fig. 3).

The main objective concerned the creation of an experiential itinerary, organized by a sensitive narration that starts in the own act of its fruition, such as to allow the observer a critical interaction depending on the knowledge process of the works and the geometries evoked by their spaces. The installation includes the projection of multimedia contents, to be displayed on semi-transparent screens, and it can narrate the compositional structure of the works in a controlled deconstruction of the significant painted elements.

Protagonist is the video mapping: it marks the times and dynamics of a possible and credible mise-en-scène, inside an autonomous stage, hosting different multimedia systems necessary to the experience. The visitor is led by a light path and voice of an actor in catch a show that opens its perspective-linear registers, hastening the visualization of material physicality of the environments, in which the protagonists of the works are animated by geometric transformations typical of image warping.

According to this exhibition logic, this following proposes an immersive fruition path, aimed to enhancing the interaction and knowledge of the inestimable artistic and cultural heritage offered by Tintoretto's works, in a close to theatrical dynamics approach [Propedo 2020]. A stage, extended along the short side of the room and about 26 meters long, rises from the floor to a height of 1.4 meters to allow viewers to frame the three works showed and po-

Fig. 3. Exhibition setting proposal, Sala Capitolare of the Scuola Grande di San Marco,Venic (Thomas William
Propedo, 2020).
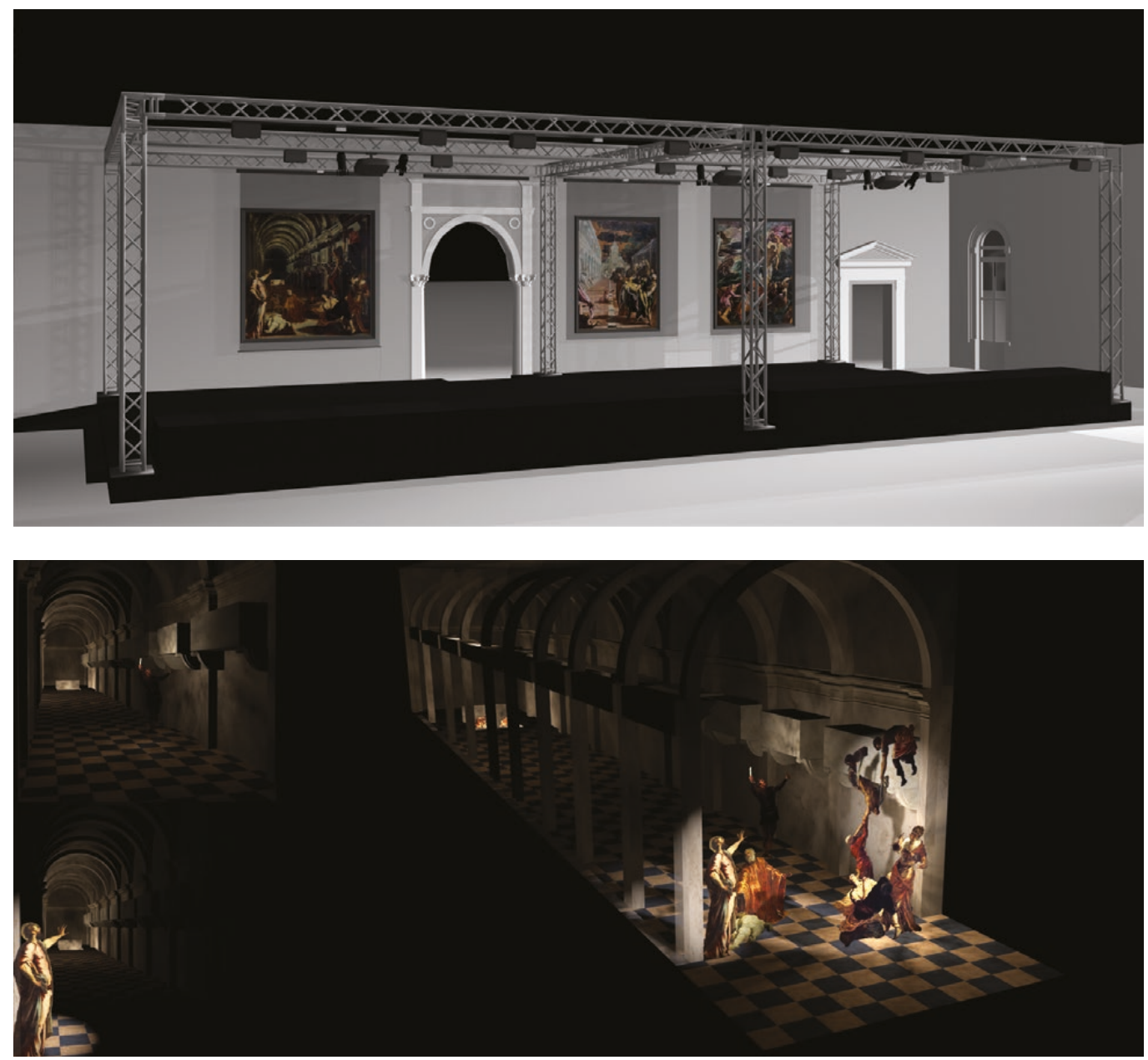
sitioned in their original location, so as to enjoy them from their correct points of view. But this happens only at the conclusion of a specific narrative experience that anticipates the digital act of knowledge, mediated by a filter on which animated sequences are projected. It is possible to enter in the dark room guided by the cone of light emitted by a spotlight that invites the viewers group to place themselves in the correct positions, each equipped with people counter sensors that have the purpose of monitoring the access flow and activating the video projections on motorized semi-transparent screens, placed parallel and at a very short distance from the canvases.

\section{Conclusions}

The experience is combined by the voice of an actor, involved in three performing acts aimed at the decomposition and reconstruction of the peculiar characteristics of the works: the first one recalls the historical context and the significant steps that determined its realization, the second one describes the scene and the character roles involved in it, the third one analyses the pictorial, perspective and light techniques used by the artist (fig. 4).

The scene space questions the value of virtual and augmented reality devices, commonly understood as interaction filters with real artefacts, to enhance the learning act about the works which, in this case, are only revealed in all their tangible originality at the end of the experience. The expectation activated by the entertainment, planned within an multimedia guided scene, is confronted with the astonishment of the direct works observation, inviting to reflect on their skiagraphy knowledge, just when the lights turn on and every filter disappears to reveal and paying tribute to the inestimable originality of Tintoretto's tangible works. Even if the place appointed to host them, "the same for which they were created and which declares their unitary conception, preserved from generation to generation, and so to speak from brush to brush, therefore has become over time less important than the processes of musealisation and decontextualization of works of art" [Settis 2017, p. 37].

\section{References}

De Vecchi Pierluigi (1972). Invenzioni sceniche e iconografia del miracolo nella pittura di Jacopo Tintoretto. In L'Arte, 17, pp. I0I- I32.

Frank Martina (1996). Architetture nelle opere di Jacopo Tintoretto. In Rossi Paola, Puppi Lionello (eds.). Jacopo Tintoretto nel quarto centenario della morte. Padova: Il Poligrafo, pp. 235-239.

Grosso Marsel, Guidarelli Gianmario (2019). Tintoretto and Architecture. Venezia: Marsilio.

Marinelli Sergio ( 1980). La costruzione dello spazio nelle opere di JacopoTintoretto. In Dalai Emiliani Marisa (ed.). La prospettiva rinascimentale. Codificazioni e trasgressioni. Firenze: Centro Di, pp. 319-330.

Matile Michael (1996). Quadri laterali, ovvero conseguenze di una collocazione ingrata. Sui dipinti di storie sacre nell'opera di Jacopo Tintoretto. In Venezia Cinquecento, 6 (12), pp. 15I-206.

Propedo Thomas William (2020). Visualizing Tintoretto. Venezia: Università luav di Venezia, Tesi di laurea magistrale in Design del prodotto e della comunicazione visiva, relatore: Massimiliano Ciammaichella, correlatrice: Gabriella Liva.

Ridolfi Carlo (1648). Delle Meraviglie dell'Arte, overo delle vite degli illustri pittori veneti e dello stato. Descritte dal Cavalier Carlo Ridolfi. Parte seconda. Al molto Illustre Signor Bortolo Dafino. Venezia: Gio. Battista Sgava.

Settis Salvatore (2017). Tintoretto torni a San Marco. In II Sole 24 Ore, 23 aprile, p. 37.

Weddigen Erasmus (199I). II secondo Pergolo di San Marco e la Loggetta del Sansovino: preliminari al Miracolo dello schiavo di Jacopo Tintoretto. In Venezia Cinquecento, I (I), pp. I0I-I29.

\section{Authors}

Gabriella Liva, Dept. of Architecture and Arts, luav University of Venice, gabriella.liva@iuav.it

Massimiliano Ciammaichella, Dept. of Architecture and Arts, luav University of Venice, massimiliano.ciammaichella@iuav.it 
